Revision for Agriculture, Ecosystems and Environment (No. AGEE16093 R2)

Text information: Abstract: 306; Text: 4, 448; References: 32; Tables: 2; Figures: $\underline{3}$

\title{
Title: Traditional grazing regimes promote biodiversity and increase nectar production in Tibetan alpine meadows
}

Authors: Junpeng $\mathrm{Mu}^{1,2}$, Yuling Zeng ${ }^{1}$, Qinggui Wu ${ }^{1}$, Karl J. Niklas ${ }^{3}$ \& Kechang $\mathrm{Niu}^{2}{ }^{2}$ *

1. Ecological Security and Protection Key Laboratory of Sichuan Province, Mianyang Normal University, Mianyang 621000, China;

2. Department of Biology, Nanjing University, Nanjing 210023, China

3. Plant Biology Section, School of Integrative Plant Science, Cornell University, Ithaca, NY 14853, USA

* Corresponding author. E-mail: kechangniu@nju.edu.cn

Running head: Grazing promotes nectar production 
Pastoralists claim that traditional management practices involving light to moderate grazing ensure sustainable yield and promote the multifunctional services provided by rangeland ecosystems. Nectar production is a key ecosystem function crucial to successful apiculture and to the sustainability of services provided by pollinators in the Tibetan alpine rangeland. Here, we evaluated whether traditional (light to moderate) grazing promotes plant biodiversity and nectar production at the level of individual plants and at the level of an entire community. We compared plant species diversity and nectar production of the dominant nectariferous species (Saussurea nigrescens) at the individual plant level and at the community level in ungrazed, lightly grazed, moderately grazed, and heavily grazed plots in each of three Tibetan alpine meadow sites. Individual nectar production was quantified as nectar volume $\times$ floret number per capitulum $\times$ capitulum per plant. Community nectar production was calculated as individual nectar production $\times$ the number of flowering plants per $1.0 \mathrm{~m}^{2}$ plot. We found that nectar production at the floret, individual, and community levels was significantly higher in lightly and moderately grazed plots compared to heavily grazed or ungrazed plots. This somewhat counterintuitive observation (particularly with regard to ungrazed plots) resulted from the fact that light and moderate grazing increased floret and capitulum number, and the number of flowering individuals per plot as a result of lowered competition for light. Moreover, species richness was significantly correlated with nectar production (as a result of light to moderate grazing) both at the individual level and at the community level. These results support the traditional view that light to moderate grazing not only promotes plant biodiversity but also ensures a sustainable yield in nectar production (and forage). Thus, traditional grazing management practices are more "eco-friendly" 
compared to recent and widespread practices involving either grazing exclusion or overgrazing in the Tibetan rangelands examined in this study.

Key words: apiculture, community biodiversity, ecosystem function, ecosystem services, land use change, nectariferous plant, Tibetan Plateau 


\section{Introduction}

The rangelands of the Tibetan Plateau have provided many diverse ecosystem services to local and regional agriculture for thousands of years (Miehe et al., 2009). However, changes in climate (e.g. warming) and in land use practices (e.g. nitrogen deposition) over the past three decades have jeopardized the sustainability of these rangelands (Harris, 2010; Niu et al., 2016) both in terms of natural services (e.g., nectar production for indigenous insect pollinators) and agricultural services (e.g., the production of grazing crops for agriculture) (Bennett et al., 2009; Niu et al., 2016). The linkages between natural and agricultural services are complex and at times problematic. For example, based on grazing practices over hundreds of years, traditional Tibetan pastoralists believe that light to moderate grazing ensures sustainable forage yields and actually promotes the otherwise diverse natural services grasslands provide (e.g. biodiversity and nectar production) (Yeh, 2005; Niu et al., 2016) .The production of nectar is crucial not just to native insect pollinators but also to apiculture, which has become a key industry in the eastern Tibetan rangeland over the last three decades (Mu et al., 2014). In contrast, there is some evidence that overgrazed (or ungrazed) rangelands yield a greater nectar production in large part because both land use practices favor the growth of nectariferous forbs species albeit with a detrimental effect on biodiversity (Xie et al., 2008). Unfortunately, to the best of our knowledge, there are no empirical evaluations of the effects of different grazing practices on both nectar production and species diversity. To fill this gap, we examined whether traditional Tibetan grazing practices (i.e., light to moderate grazing) are more beneficial to nectar production and biodiversity compared to overgrazing and grazing exclusion practices. 
In our previous studies in the rangeland of the eastern Tibetan Plateau, we found that traditional light and moderate grazing often promotes flowering and increases reproductive allocation at the individual plant level but with a reduction in the height of the vegetative canopy (Niu et al., 2009; Zhang et al., 2014; Niu et al., 2015). Based on these results, light to moderate grazing could promote nectar production via diverse ways, including: (i) early flowing promoted by grazing (Zhang et al., 2014); (ii) increases in floret and capitulum number with increasing individual size and reproductive biomass (Niu et al., 2009, Mu et al., 2014); (iii) increases in flowering individuals and plant density (Mu et al., 2014) that will increase nectar production at the community level; and (iv) promote more and longer visits of pollinators with increased nectar production, species diversity and density (Mitchell et al. 2004), coupled with a reduction in the vegetative canopy.

Because Saussurea nigrescens (Compositae) is the dominant nectariferous species and subdominant species in the plant community available for study (Mu et al., 2014), we focused on this species to measure plant traits and nectar production in ungrazed, lightly grazed, moderately grazed, and heavily grazed plots at three independent sites in the alpine meadows and examined whether (i) light to moderate grazing promotes nectar production at the individual as well as community level, (ii) changes in nectar production in response to a grazing regime correlate with a change in either nectar volume or concentration, floret or capitulum number, or a change in the number of flowering individuals, and (iii) change in nectar production at the individual or community level correlates with a change in species diversity. 


\section{Materials and methods}

\subsection{Study sites}

The three alpine meadow sites selected for this study are located in Hongyuan County $\left(32^{\circ} 48^{\prime}-32^{\circ} 52^{\prime} \mathrm{N}, 102^{\circ} 01^{\prime}-102^{\circ} 33^{\prime} \mathrm{E}\right)$, Sichuan province, at the eastern Tibetan Plateau, with altitudes ranging from 3400 to $3600 \mathrm{~m}$. The climate is cold, continental, and characterized by a short and cool spring, summer, and autumn, and a long frosty winter. The mean annual temperature is $0.95{ }^{\circ} \mathrm{C}$ with maximum and minimum monthly means of $10.2^{\circ} \mathrm{C}$ and $-5.3^{\circ} \mathrm{C}$ in July and January, respectively. The annual mean precipitation is $744 \mathrm{~mm}$ with $80 \%$ occurring from May to August, over the last three decades (Wu et al., 2011). To ensure sustainable forage yields in the region, rotational grazing by yaks among pastures has been managed by three to eight collaborating families over the last hundred years. This practice involves light to moderate grazing of the entire rangeland (Cao et al., 2013). However, since the 2000s, overgrazed pastures in the landscape have become common, especially in public pastures (Cao et al., 2013). In the last decade, attempts by the government to restore the indigenous biodiversity have led to excluding grazing in some pastures. The three sites selected for this study are representative of all four grazing practices (i.e., light, moderate, and overgrazed pastures, and grazing-excluded pastures).

The average height of the community canopy in our study sites ranges from 20 to $50 \mathrm{~cm}$; vegetative cover often exceeds $80 \%$ (Wu et al., 2011). The main soil types are alpine meadow soil (with a high organic content, low total $\mathrm{N}$ and $\mathrm{P}$ ), and a peat layer ranging from $10-40 \mathrm{~cm}$ in thickness (Liu et al., 2011). The native bee species (e.g. Apis cerana, Bombus filchnerae, B. humilis, and B. supremus) were the major pollinators (Mu et al., 2014). However, since the 
1980s, the dominant bees are mostly Apis cerana before 2000 and Apis mellifera subsequently. These two species have been introduced for an ever expanding apiculture industry (Sun et al., 2013).

\subsection{Measurements of plant morphometric traits and nectar production}

In each of our three sites, we selected four adjacent pastures (ranging from five to 20 ha) subjected to four different grazing intensities (i.e. ungrazed, lightly grazed, moderately grazed, and over grazed). In 2014, most of the livestock were move to pastures in higher elevations from late May to September (Niu et al., 2016). At that time, five $1 \mathrm{~m} \times 1 \mathrm{~m}$ plots were randomly established in each of four pastures to measure nectar production, plant traits, and community composition (details regarding the location of the sites and plots are provided in Supplemental Materials Fig. S1). The grazing intensity was indicated by residual aboveground biomass and yak density. Specifically, light grazing, moderate grazing, and overgrazing results in $65-80 \%, 50-60 \%$, and $25-30 \%$ aboveground biomass relative to ungrazed plots, respectively (Gao et al., 2011). Yak densities differ in pastures experiencing light grazing, moderate grazing, and overgrazing $\left(1.2\right.$ yaks ha $^{-1}, 2.0$ yaks ha $^{-1}, 2.9$ yaks ha $^{-1}$, and 0.0 yaks ha ${ }^{-1}$, respectively).

The plants of $S$. nigrescens grow to between 15 and $40 \mathrm{~cm}$ in height. Each produces a single inflorescence that produces up to 2-5 capitula, each containing 20-55 florets bearing an annular bowl-shaped nectary that lies between the ovary and the anthers. Plants of $S$. nigrescens turn green in mid-May and senesce by the middle of September. Anthesis starts in late July and ends in late August. In July 2014, we recorded the number of flowering and non-flowering $S$. nigrescens individuals in each plot. Simultaneously, we measured 
community canopy height and the species abundance (gauged by the relative coverage of each species in each plot). From late July to early August of 2014, during the peak $S$. nigrescens flowering season, we measured floret nectar volumes and concentrations. In each plot, we randomly selected 3-30 healthy plants and measured the number of capitula, the number of florets per capitulum, nectar volumes and concentrations, and aboveground plant biomass (the protocols are provided by $\mathrm{Mu}$ et al $(2014,2015)$. Nectar volume was measured for one floret per capitulum using $1 \mu \mathrm{l}$ or $5 \mu \mathrm{l}$ micropipettes (Hirschmann Laborgeräte, Germany). Nectar concentration (sucrose content, $c f$. Mu et al., 2015) was concurrently measured with a hand refractometer (Eclipse, Stanley Company, England Bellingham, UK) following Johnson et al. (2006). The sample sizes for measuring the foregoing morphological traits, and nectar volume and concentration measurements are provided in supplementary material Table S1.

\subsection{Data analyses}

In each plot, we calculated species richness based on three metrics (Jost, 2006): (i) the total number of species, (ii) the Shannon entropy of species diversity, and (iii) the Simpson index of species evenness based on species number and the relative coverage of each species (Summarized in Table S2) using the 'vegetarian' package (Charney and Record, 2009) in R. The proportion of flowering plants of $S$. nigrescens was calculated as the number of flowering individuals divided by the total number of individuals in each plot. Individual nectar productivity was calculated as nectar volume per floret $\times$ floret number per capitulum $\times$ capitulum number per plant, averaged across the 3-30 individuals sampled per 
plot. Community nectar productivity was calculated as the mean individual nectar productivity $\times$ the number of flowering individuals per plot.

We used two-way ANOVA to quantify the relative importance and significance of site effect, grazing intensity per plots on the variation of nectar production, species diversity and plant density, and each of the morphometric functional traits. Since there is no significant interaction between site and grazing treatment for all of the variables of interest, we nested grazing treatment in the site effect in our two-way ANOVA. We then used a linear mixed effect model with residual maximum likelihood as a multiple comparison to measure the strength and direction of the site and grazing effect. The linear mixed effect model took the form 'response variable $\sim$ site + grazing intensity, random $=\sim 1 \mid$ plot', wherein the species diversity indices, nectar production, and plant traits and density were included as the response variables along with 'grazing' and 'site' factors. The 'individual plot' was taken as a random factor to account for any spatial autocorrelation. Model comparisons were based on Akaike Information Criteria (AIC). The lme4 package in $\mathrm{R}$ was used to perform the linear mixed effect model analyses (Bates et al., 2011). We used generalized canonical discriminant analyses (gCCA) with a nested linear-mixed effect model ('grazing' nested in 'site effect') to examine and visualize linkages among plant traits and density, which determined nectar production over grazing treatments across the three sites. The gCCA were performed using the candisc package (Friendly and Fox, 2013). Finally, we used a linear regression model to examine the extent to which nectar production and species diversity were correlated across the four grazing treatments within each of the three sites. When necessary, the data were log-transformed to meet the assumptions of normality and homogeneity of variance. All 
statistical analyses were performed in $\mathrm{R}$ ( $\mathrm{R}$ Development Core Team 2015, URL http://www.R-project.org/).

\section{Results:}

\subsection{The effect of grazing intensity on species diversity and nectar production}

As expected, variations in species diversity were predominantly attributable to the grazing effect, rather than to site differences (Table 1), with significantly higher species richness and species diversity indices in lightly and moderately grazed plots compared to ungrazed or heavily grazed plots (Table 2; Fig 1a - b). Species evenness and canopy height differed among the four sites (Table 1) and increased as a function of grazing intensity (Table 2). The grazing effect accounted for between $79 \%$ and $90 \%$ of the variation in nectar production (Table 1), with lightly and moderately grazed plots manifesting significantly higher nectar production compared to the ungrazed or grazed plots, both at the individual level and at the community level (Fig. 1c-d).

\subsection{Plant morphometric traits and abundance in response to grazing intensity}

The grazing effect accounted for most of the variation observed for nectar volume, floret number, capitulum number, and individual size (Table 1). Light and moderate grazing promoted larger nectar volume and larger numbers of florets and capitula per individual relative to ungrazed and heavily grazed plots (Table 2). Compared to ungrazed plots, individual plant size (height) decreased in traditionally grazed plots and, as expected, significantly decreased in heavily grazed plots (Table 2, Fig. 2). In contrast, neither the grazing effect nor the site effect had a significant influence on nectar concentration (Table 2, 
Fig. 2); both accounted for only a small amount of the variation in nectar concentration (Table 1).

The grazing effect accounted for most of the variation observed in plant density and the proportion of flowering plants (Table 1), with lightly and moderately grazed plots manifesting significantly higher plant densities and proportions of flowering plants relative to ungrazed and heavily grazed plots (Table 1, Fig. 2). The first axis of the gCCA (Table 2), which accounts for $89.4 \%$ of the variance observed for the variables of interest $(P<0.001$ in MANOVA), showed that increases in the morphometric traits and in abundance coupled with higher species diversity (but low species evenness) distinguished lightly and moderately grazed plots from ungrazed and heavily grazed plots (Fig. 2).

\subsection{Relationship between species diversity and nectar production}

Regardless of the grazing treatment, we observed a strong positive correlation between species diversity and nectar production both at the individual level and at the community level (Fig. 3a-b), although the strength of the correlation declined $\left(r^{2}=0.14 \sim 0.32, P<0.001\right)$ when species diversity was gauged by Shannon entropy. A significantly negatively correlation was observed between species evenness and nectar production both at the individual level $\left(r^{2}\right.$ $=0.72, P<0.01)$ and at the community level $\left(r^{2}=0.64, P<0.01\right)$.

\section{Discussion}

\subsection{Why does the traditional grazing regime promote individual nectar production?}

Although grazing is anticipated to reduce reproductive biomass and nectar production ( Díza et al., 2007; Niu et al., 2009), our results show that traditional light to moderate grazing 
promotes individual plant nectar production as a result of increasing the numbers of florets and capitula produced per individual plant. Nevertheless, the size of individual plants and their inflorescences decreased relative to plant height and biomass under light to moderate grazing relative to ungrazed and heavily grazed plots. Although these results may appear to be contradictory, our data indicate that, compared to individual plants growing in ungrazed or heavily grazed conditions, plants growing under light to moderately grazed conditions produce many more (but smaller) florets and capitula by increasing their biomass allocation to reproductive biomass (Niu et al., 2009, 2012).

A number of interactions between biomass allocation patterns and grazing can account for these results. For example, plants growing in ungrazed plots tend to grow tall due to competition for light, whereas grazing reduces light competition and thereby promotes a reduction in allocation to stem and leaf biomass with a concomitant increase in reproductive biomass (Niu et al., 2009, 2012), which according to our data not only increases the biomass allocation to floret and nectar production but also promotes earlier flowering (Zhang et al., 2014). Arguably, for energetic reasons, it is reasonable to speculate that this shift in allocation might increase nectar volume rather than nectar quality per individual because it is more "expensive" to increase nectar concentration, which is precisely what we observe for plants growing under light to moderate grazing conditions. An additional contributing factor is that individual plants can attract more pollinators by producing more (but not better quality) nectar under open canopy conditions and high species diversity and abundance. In contrast, under heavy grazing conditions, individual plants allocate more biomass to vegetative regrowth, which depresses biomass allocation to flowers and nectar production and quality 
(Southwick, 1984; Búrquez and Corbet, 1991, 1998; Mu et al., 2015).

\subsection{Why does the traditional grazing regime promote community-wide nectar production?}

From a strictly logical perspective, growing conditions that increase nectar production and flower number at the plant level should increase both of these attributes at the community-wide level even in the absence of any increase in plant species diversity. This speculation is supported by our data. The increase in the number of flowers per individual plant was attended by an increase in the number of individual $S$. nigrescens plants. This phenomenon, which has been reported in other studies, indicates that light to moderate grazing releases $S$. nigrescens from competition with grasses and other tall forb species (Niu et al., 2015).

Another contributing factor to a community-wide increase in nectar production is that light to moderate grazing increases the proportion of flowering plants. There are three biologically reasonable explanations for this: i) decreasing individual size and accelerating flowering time may be an effective strategy to compensate for grazing (Díaz et al., 1994); ii) decreased plant-plant competition may promote an earlier allocation of energy and resources to reproduction (Augustine et al., 1998; Niu et al., 2009); iii) grazing promotes an open canopy that supports faster growth and early reproduction as a result of increasing photosynthesis (Parsons et al., 1983). It is also possible that moderate grazing promotes higher biodiversity and increases the number of individuals producing flowers because of decreased competition for limited light (Zhang et al., 2014; Niu et al., 2015; Vermeulen, 2015). An additional factors is that open communities with high diversity and a greater number of flowering individuals tend to attract more abundant and diverse pollinators, which 
induces nectar production as a reward.

\section{Conclusion}

Recent rapid changes in rangeland management in China and elsewhere have challenged the balance between maintaining the diverse services ecosystems provide and agricultural necessity (Petz et al., 2014). Here, we show that traditional grazing practices not only promote plant biodiversity but also increase nectar production both at the individual plant and community levels as a consequence of adaptive changes in biomass and energy allocation patterns, whereas overgrazing and grazing exclusion have the opposite effects. Specifically, in our study sites, traditional grazing supports two major ecosystem services: i) it promotes a sustainable production of forage, and ii) it increases nectar production that is beneficial to apiculture as well as native insect pollinators. Thus, traditional grazing practices provide a balance between the natural and agricultural services that the rangeland ecosystem provides.

The results reported here may, at least in theory, provide a lesson to maintaining the multifunctionality of other rangeland ecosystems, i.e., management practices should consider examining the consequences of traditional pastoral practices before excluding grazing. For example, our results clearly show that precluding grazing actually reduces biodiversity, community productivity, and reduces the economic benefits of apiculture. Clearly, the sustainable management of rangelands requires further study. However, our study demonstrates that the consequences of some policies can be counter-intuitive and damaging.

\section{Acknowledgements}


We thank Prof. Shucun Sun for valuable discussion and constructive comments on earlier versions of this manuscript. We are especially grateful to Dr. Xinwei Wu, Hui Wang, Xu Luo, Yanling Luo, and Kai He for providing invaluable field and laboratory assistance. The study was supported by National Science Foundation of China (no 31270513 to MJP and no 31370008 to NKC), Innovative Research Team by Sichuan Provincial Department of Education (no 13TD0015) and National Basic Research Program of China (no 2013CB956304).

\section{References}

Augustine, D. J., L. E. Frelich, P. A. Jordan. 1998. Evidence for two alternate stable states in an ungulate grazing system. Ecological Applications 84:1260-1269.

Bates, D., M. Maechler, and B. Bolker. 2011. lme4: Linear mixed-effects models using S4 classes. R package version $0.999375-38$.

Bennett, E. M., G. D. Peterson, and L. J. Gordon. 2009. Understanding relationships among multiple ecosystem services. Ecology Letters 12:1394-1404

Búrquez, A., S. A. Corbet. 1991. Do flowers reabsorb nectar? Functional Ecology 5:369-379.

Búrquez A, S. A. Corbet. 1998. Dynamics of production and exploitation of nectar: lessons from Impatiens glandulifera Royle. In: B. Bahadur (Ed.), Nectary biology (pp. 130-152). Nagpur, India: Dattsons.

Cao, J., E. T. Yeh, N. M. Holden, Y. Yang, and G. Du. 2013. The effects of enclosures and land-use contracts on rangeland degradation on the Qinghai-Tibetan plateau. Journal of Arid Environments 97:3-8.

Charney, N., and S. Record. 2009. Jost Diversity Measures for Community Data. R Package "Vegetarian" version 1.2. 
Díza S, A. Acosta, M. Cabido. 1994. Grazing and the phenology of fFlowering and fruiting in a montane grassland in Argentina: A niche approach. Oikos 70:287-295.

Díza, S., S. Lavorel, S. McIntyer, V. Falczuk, D. Milchunas, F. Casanoves, H. Clark, C. Skarpe, G. Rush, M. Sternberg, I. Noy-Meir, J. Landsberg, J. Zhang, H. Clark, and B. D. Campbell. 2007. Plant trait responses to grazing-a global synthesis. Global Change Biology 13:313-341.

Friendly, M., and J. Fox. 2013. Visualizing Generalized Canonical Discriminant and Canonical Correlation Analysis. R Package "candisc" version: 0.6-5.

Gao, Y., M. Schumann, X. Zeng, and H. Chen. 2011. Changes of plant communities and soil properties due to degradation of alpine wetlands on the Qinghai-Tibetan plateau. Applied Ecology and Environmental Research 63: 67-77.

Harris, R. B. 2010. Rangeland degradation on the Qinghai-Tibetan plateau: a review of the evidence of its magnitude and causes. Journal of Arid Environments 74:1-12.

Jost, L. 2006. Entropy and diversity. Oikos 113:363-375.

Li, G., Y. Liu, L. E. Frelich, and S. Sun. 2011. Experimental warming induces degradation of a Tibetan alpine meadow through trophic interactions. Journal of Applied Ecology 48: 659-667

Liu, Y., P. B. Reich, G. Li, and S. Sun. 2011. Shifting phenology and abundance under experimental warming alters trophic relationships and plant reproductive capacity. Ecology 92:1201-1207.

Miehe, G., S. Miehe, K. Kaiser, C. Reudenbach, L. Behrendes, and F. Schlütz. 2009. How old is pastoralism in Tibet? An ecological approach to the making of a Tibetan landscape. Palaeogeography, Palaeoclimatology, Palaeoecology 276:130-147.

Mitchell, R., J. Karron, K. Holmquist, and J. Bell. 2004. The influence of Mimulus ringens floral display size on pollinator visitation patterns. Functional Ecology 18:116-124. 
Mu, J., Y. Peng, X. Xi, X. Wu, J. N. Griffin, K. J. Niklas, and S. Sun. 2014. Domesticated honey bees evolutionarily reduce flower nectar volume in a Tibetan lotus. Ecology 95:3161-3172.

Mu, J., Y. Peng, X. Xi, X. Wu, G. Li, K. J. Niklas, S. Sun. 2015. Artificial asymmetric warming dramatically reduces nectar production in a Tibetan lotus. Annals of Botany 116:899-906

Niu, K. C., P. Choler, B. B. Zhao, and G. Z. Du. 2009. The allometry of reproductive biomass in response to land use in Tibetan alpine grasslands. Functional Ecology 23:274-283.

Niu, K. C., J.-S. He, S. T. Zhang, and M. J. Lechowicz. 2015. Grazing increases functional richness but not functional ivergence in Tibetan alpine meadow plant communities. Biodiversity and Conservation. DOI 10.1007/s10531-015-0960-2.

Niu, K. C., J. S. He, S. Zhang, and M. J. Lechowicz. 2016. Tradeoffs between forage quality and soil fertility: Lessons from Himalayan rangelands. Agriculture, Ecosystems \& Environment doi:10.1016/j.agee.2016.1004.1023.

Niu, K. C., B. Schmid, P. Choler, and G. Z. Du. 2012. Relationship between reproductive allocation and relative abundance among 32 species of a Tibetan Alpine Meadow: effects of fertilization and grazing. PLoS ONE 7:e35448.

Parsons A. J., E. L. Leafe, B. Collett, W. Stiles. 1983. The physiology of grass production under grazing. I. characteristics of leaf and canopy photosynthesis of continuously-grazed Swards. Journal of Applied Ecology 20:117-126.

Petz, K., R. Alkemade, M. Bakkenes, C. J. E. Schulp, M van der Velde, R. Leemans. 2014. Mapping and modelling trade-offs and synergies between grazing intensity and ecosytem services in rangelands using global-scale datasets and models. Global Enviromental Change 29:223-234.

Southwick E. E. 1984. Photosynthate allocation to floral nectar: a neglected energy investment. Ecology 
65:1775-1779.

Sun, S.-G., S.-Q. Huang, and Y.-H. Guo. 2013. Pollinator shift to managed honeybees enhances reproductive output in a bumblebee-pollinated plant. Plant systematics and evolution 299:139-150.

Vermeulen, P. J. 2015. On selection for flowering time plasticity in response to density. New Phytologist, 205(1), 429-439.

Wu, X., J. E. Duffy, P. B. Reich, and S. Sun. 2011. A brown-world cascade in the dung decomposer food web of an alpine meadow: effects of predator interactions and warming. Ecological Monographs 81:313-328.

Xie, Z., P. H. Williams, and Y. Tang. 2008. The effect of grazing on bumblebees in the high rangelands of the eastern Tibetan Plateau of Sichuan. Journal of Insect Conservation 12:695-703.

Yeh, E. T. 2005. Green governmentality and pastoralism in western China:'Converting pastures to grasslands'. Nomadic Peoples 9:9-30.

Zhang, Z. L., K. C. Niu, X. D. Liu, P. Jia, and G. Z. Du. 2014. Linking flowering and reproductive allocation in response to nitrogen addition in an alpine meadow. Journal of Plant Ecology 7:231-239. 
1 Table 1 The relative importance of "site effect" vs. "grazing effect" on variation in

2 community biodiversity, nectar production, and plant morphometric traits and abundance as

3 determined by two way ANOVA with grazing treatment nested in site effect. Bold entries

$4 \quad$ indicate significant effect $(P<0.05)$ of site effect or grazing effect. *** indicates $P<0.001$.

\begin{tabular}{|c|c|c|c|}
\hline & \multicolumn{3}{|c|}{ Percentage of variability (\%) } \\
\hline & $\begin{array}{r}\text { Site } \\
\text { effect }\end{array}$ & $\begin{array}{l}\text { Grazing } \\
\text { intensity }\end{array}$ & $\begin{array}{r}\text { Residuals } \\
\text { (Plots) }\end{array}$ \\
\hline \multicolumn{4}{|l|}{ Community attribute } \\
\hline Species diversity & 3.53 & $61.23 * *$ & 35.24 \\
\hline Species richness & 0.01 & $93.60 * *$ & 6.39 \\
\hline Species evenness & 2.00 & $90.09 * *$ & 7.91 \\
\hline Canopy height & $1.87 * *$ & $89.96 * *$ & 8.16 \\
\hline \multicolumn{4}{|l|}{ Nectar production } \\
\hline Individual nectar production & 0.11 & $97.05 * *$ & 2.83 \\
\hline Community nectar production & 0.25 & $79.60 * *$ & 20.15 \\
\hline \multicolumn{4}{|c|}{ Plant morphometric trait and abundance } \\
\hline Nectar volume & 0.16 & $92.35 * *$ & 7.49 \\
\hline Nectar concentration & 2.70 & 9.00 & 88.30 \\
\hline Floret number & 0.46 & $76.20^{* *}$ & 23.34 \\
\hline Capitulum number & 0.25 & $70.77 * *$ & 28.98 \\
\hline Individual size & 1.13 & $93.18^{* *}$ & 5.69 \\
\hline Plant density & 0.05 & $85.21 * *$ & 14.74 \\
\hline Proportion of flowering plants & 0.25 & $65.19 * *$ & 34.56 \\
\hline
\end{tabular}

5 
6 Table 2 Summary of effect of grazing intensity (nested in sites) on community and plant 7 morphometric traits, nectar production, and abundance. The effect was test by linear-mixed 8 effect model with grazing effect nested in site effect. The tabulated values indicate the strength of the grazing (and site) effect gauged by the slope of the relationship (slope value +/- SD). Bold entries indicate $P<0.05$; * denotes $P<0.01$. Positive and negative values indicate increased versus decreased effects in site 2 and 3 relative to site 1, or grazed plots relative to ungrazed plots, respectively. AIC: Akaike information criterion, Degrees of Freedom $=60 . \mathrm{DF}=2($ sites $) / 9($ grazed treatments $) / 48($ plots $)$.

\section{Site effect}

(relative to Site 1 )

AIC Site $2 \quad$ Site 3

\section{$+2$ \\ Community attribute}

\begin{tabular}{|c|c|c|c|c|c|c|}
\hline Species diversity & -67.9 & $0.04 \pm 0.03$ & $0.06 \pm 0.03$ & $-0.005 \pm 0.04$ & $0.24 \pm 0.04$ & $-0.006 \pm 0.04$ \\
\hline Species richness & 233.4 & $-0.05 \pm 0.49$ & $-0.15 \pm 0.49$ & $5.67 \pm 0.57 *$ & $11.7 \pm 0.57 *$ & $-2.4 \pm 0.56 *$ \\
\hline Species evenness & -196.9 & $0.02 \pm 0.01$ & $0.03 \pm 0.01$ & $-0.12 \pm 0.01 *$ & $-0.11 \pm 0.01 *$ & $0.09 \pm 0.01 *$ \\
\hline Canopy height & 272.8 & $2.39 \pm 0.71$ & $0.93 \pm 0.71$ & $-5.57 \pm 0.82 *$ & $-6.35 \pm 0.82 *$ & $-18.6 \pm 0.82 *$ \\
\hline \multicolumn{7}{|l|}{ Nectar production } \\
\hline Individual & 323.1 & $0.14 \pm 0.90$ & $0.32 \pm 1.12$ & $11.9 \pm 0.18^{*}$ & $12.15 \pm 1.29 *$ & $-6.30 \pm 1.29 *$ \\
\hline Community & 759.1 & $32.8 \pm 63.0$ & $-18.2 \pm 63.0$ & $234 \pm 72.7$ & $914.3 \pm 72.8^{*}$ & $-3.67 \pm 72.7$ \\
\hline \multicolumn{7}{|c|}{ Plant morphometric trait and abundance } \\
\hline Nectar volume & -313.2 & $0.002 \pm 0.003$ & $0.003 \pm 0.003$ & $0.06 \pm 0.004 *$ & $0.06 \pm 0.004 *$ & $0.003 \pm 0.004$ \\
\hline Nectar concentration & 253.9 & $0.41 \pm 0.60$ & $0.74 \pm 0.59$ & $-0.41 \pm 0.69$ & $0.16 \pm 0.69$ & $-0.11 \pm 0.69$ \\
\hline Floret number & 272.3 & $0.65 \pm 0.68$ & $0.60 \pm 0.68$ & $8.15 \pm 0.79 *$ & $8.95 \pm 0.79 *$ & $2.71 \pm 0.79$ \\
\hline Capitulum number & 81.5 & $-0.08 \pm 0.12$ & $-0.06 \pm 0.12$ & $0.98 \pm 0.14 *$ & $1.01 \pm 0.14^{*}$ & $-0.15 \pm 0.14$ \\
\hline Individual size & -24.0 & $0.14 \pm 0.05$ & $0.064 \pm 0.05$ & $-0.07 \pm 0.05$ & $-0.01 \pm 0.05$ & $-1.25 \pm 0.05$ \\
\hline Plant density & 464.5 & $1.55 \pm 4.20$ & $1.50 \pm 4.20$ & $22.4 \pm 4.9 *$ & $66.5 \pm 4.9 *$ & $-0.93 \pm 4.9$ \\
\hline Proportion of & 438.9 & $1.09 \pm 3.30$ & $-0.92 \pm 3.30$ & $11.75 \pm 3.8^{*}$ & $32.3 \pm 3.8^{*}$ & $-0.03 \pm 3.8$ \\
\hline flowering plants & & & & & & \\
\hline
\end{tabular}

Grazing effect

(relative to ungrazed )

$\begin{array}{lll}\text { Lightly } & \text { Moderately } & \text { Heavily } \\ \text { grazed } & \text { grazed } & \text { grazed }\end{array}$




\section{Figure Legends}

Fig. 1. Effect of grazing intensity on species diversity (a-b) and nectar production of $S$. nigrescens at the individual level (c) and the community level (d) at each of the three sites. Different letters above error bars indicate significant difference among grazing treatments at each site tested by linear mixed effect with post hoc comparison.

Fig. 2. Generalized canonical discriminant analysis showing the linkages among morphometric traits of $S$. nigrescens, the proportion of flowering plants, and community attributes in response to different grazing regimes. The circles at each site bound the 95\% confidence interval around the site-treatment mean. Grazing effect is significant at $P<0.01$ by Wilks' lambda multivariate test.

Fig. 3. Correlation between species richness and nectar production of $S$. nigrescens at the individual plant level (a) and at the community level (b). 

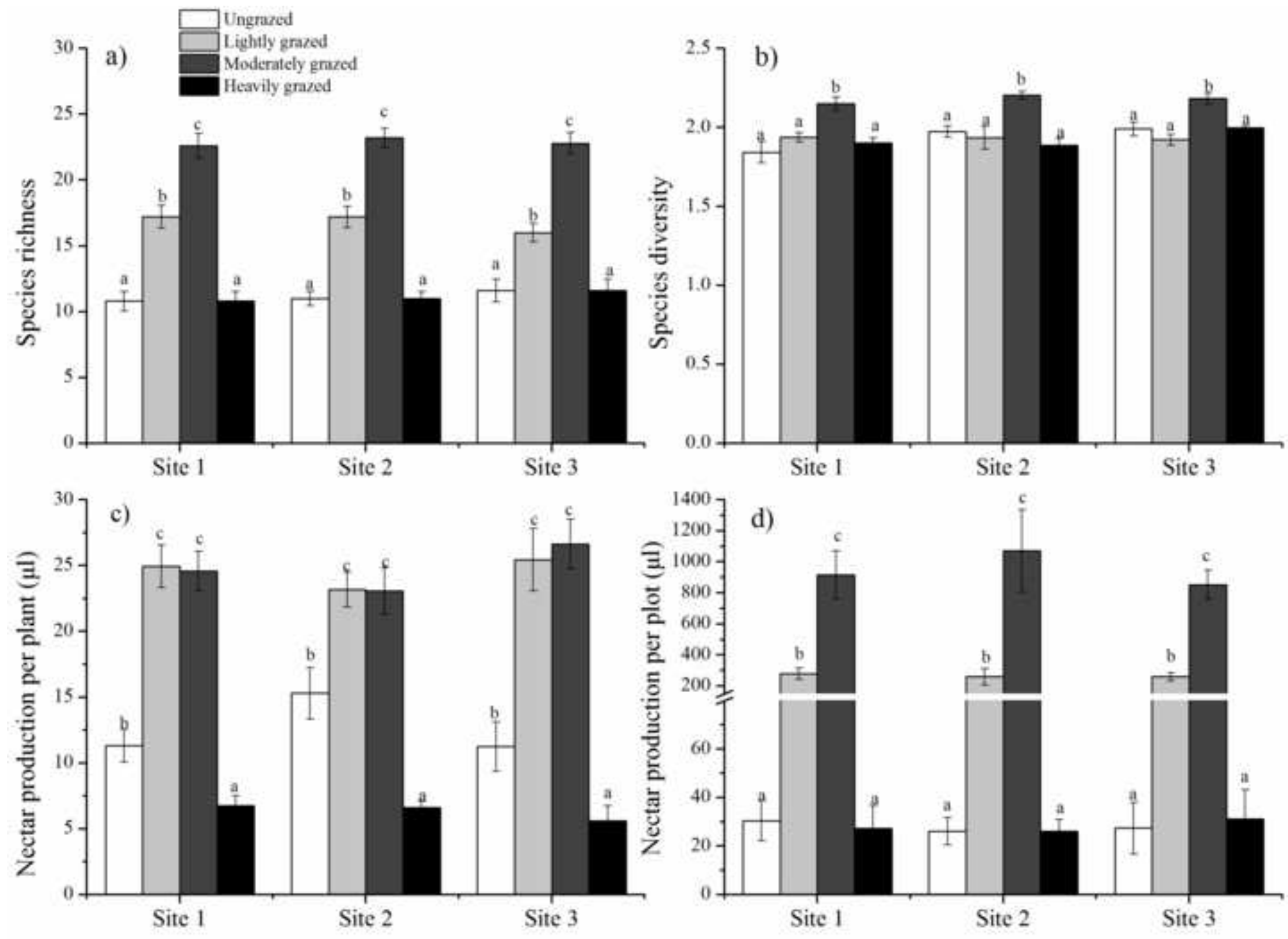


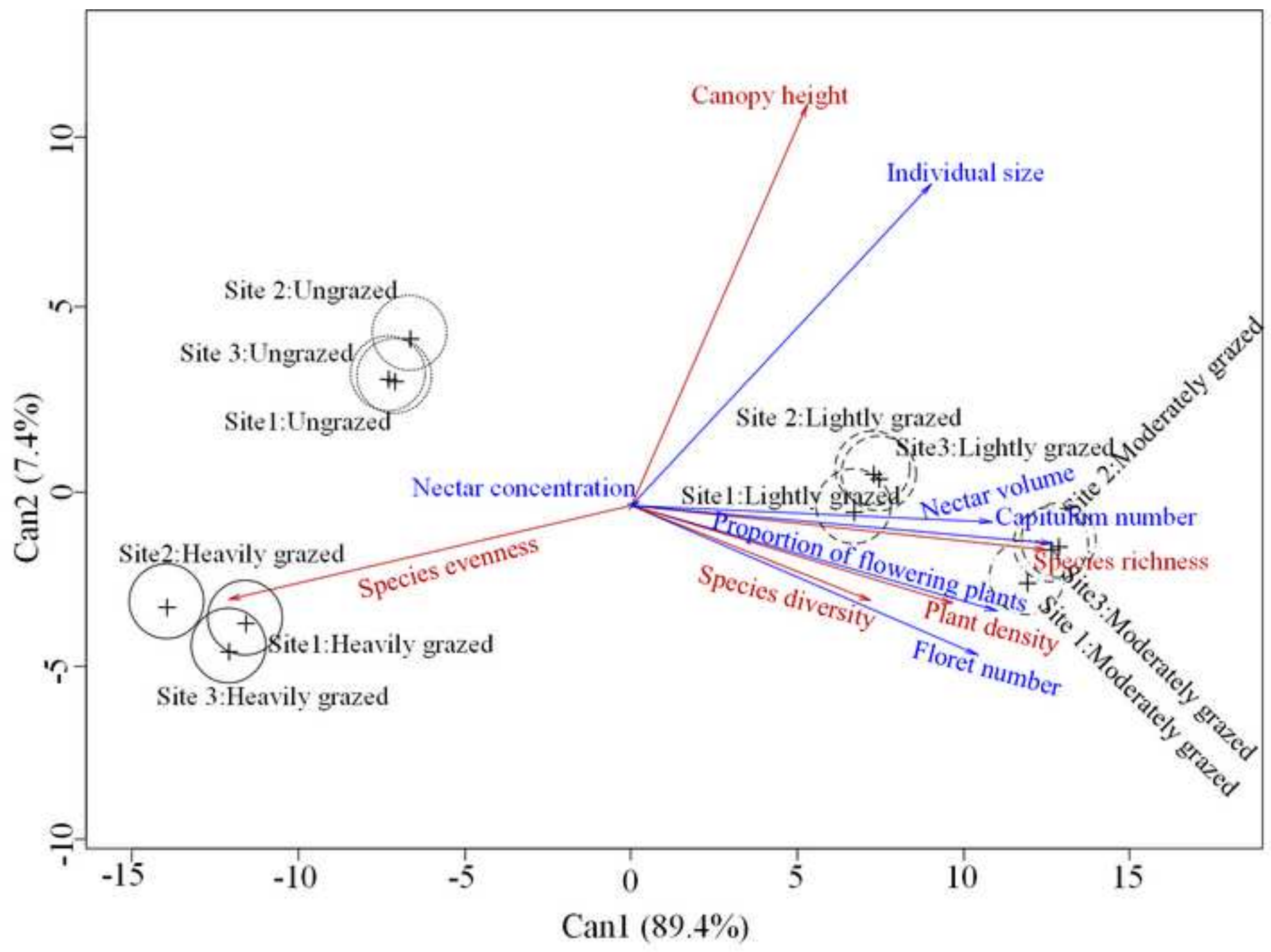



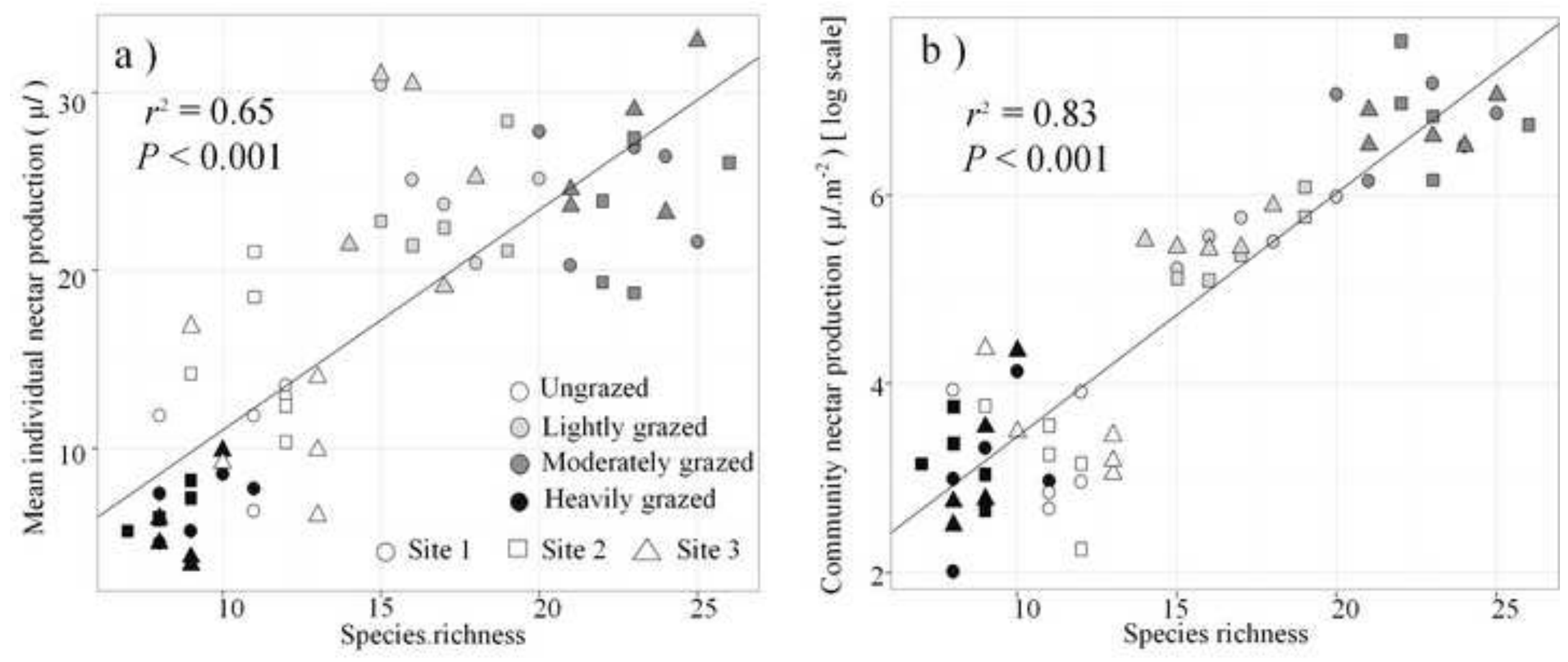